\begin{tabular}{|c|l|}
\hline Title & $\begin{array}{l}\text { Electrodeposition study on a single crystal titanium dioxide electrode : platinum on a niobium-doped titanium } \\
\text { dioxide(110) electrode }\end{array}$ \\
\hline Author(s) & Takakusagi, Satoru; Ogawa, Takafumi; Uehara, Hiromitsu; A riga, Hiroko; Shimizu, Ken-ichi; A sakura, Kiy otaka \\
\hline Citation & $\begin{array}{l}\text { Chemistry letters, 43(11), 1797-1799 } \\
\text { https://doi.org/10.1246/141.140706 }\end{array}$ \\
\hline Issue Date & 2014_11-05 \\
\hline Doc URL & http://hdl.handle.net/2115/58002 \\
\hline Type & article(author version) \\
\hline File Information & ChemLett_43_1797.pdf \\
\hline
\end{tabular}

Instructions for use 


\title{
Electrodeposition Study on a Single-crystal Titanium Dioxide Electrode: Platinum on a Niobium-doped Titanium Dioxide(110) Electrode
}

\author{
Satoru Takakusagi, $*^{1}$ Takafumi Ogawa, ${ }^{1}$ Hiromitsu Uehara, ${ }^{1}$ Hiroko Ariga, ${ }^{1}$ Ken-ichi Shimizu, ${ }^{1}$ and Kiyotaka Asakura $* 1$ \\ ${ }^{I}$ Catalysis Research Center, Hokkaido University, Kita21 Nishi10, Kita-ku, Sapporo, Hokkaido, 001-0021
}

(Received <Month $><$ Date $>,\langle$ Year $>$; CL-<No $>$; E-mail: <insert corresponding e-mail address $>$ )

$\mathrm{Pt}$ was successfully electrodeposited on a $\mathrm{Nb}$-doped $\mathrm{TiO}_{2}(110)$ electrode from a solution of $1 \mathrm{mM} \mathrm{K}_{2} \mathrm{PtCl}_{4}+50$ $\mathrm{mM} \quad \mathrm{H}_{2} \mathrm{SO}_{4}$ using single-pulse chronoamperometry. The morphology of the deposited $\mathrm{Pt}$ nanoparticles was sensitive to the deposition potential and holding time. A novel method for the preparation of metal particles on a $\mathrm{TiO}_{2}$ single-crystal surface in a controlled manner has been proposed.

Electrochemical metal deposition is widely used to prepare metal thin films, particles, and nanostructured materials on solid surfaces. Film thickness, particle size/shape, and morphology of the deposited metal can be controlled by adjusting and optimizing electrochemical conditions such as the electrode potential, holding time, and electrolyte. In contrast to electrochemical metal deposition on metal or semiconductor substrates, deposition on oxide surfaces has rarely been performed and has been limited only to oxide thin films formed on conductive substrates probably due to insufficient conductivity of oxide itself. ${ }^{1-4}$ However, the deposition of metal on an oxide surface is important for applications such as oxide-supported metal catalysts, where the catalytic properties are largely dependent both on the metal particle size/shape and on the strength of the metalsupport interaction. ${ }^{5}$ Therefore, electrochemical metal deposition on an oxide surface could be a promising method to obtain well-controlled nanoparticles on oxide surfaces and it is important to reveal the deposition mechanism.

We selected the Nb-doped $(0.05 \mathrm{wt} \%) \mathrm{TiO}_{2}(110)$ surface as a model system because of its suitability for atomic-scale surface chemistry and its sufficient conductivity. Rutile $\mathrm{TiO}_{2}$ single-crystal surfaces, particularly the (110) face, ${ }^{6,7}$ are the most studied single-crystal oxide surfaces, of which atomically flat and $\mathrm{Nb}$-doped conductive $\mathrm{TiO}_{2}(110)$ has recently become available. ${ }^{8,9}$ The electrodeposition of $\mathrm{Pt}$ on the $\mathrm{Nb}$-doped $\mathrm{TiO}_{2}(110)$ is investigated here using singlepulse chronoamperometry. To our knowledge, this is the first study of metal electrodeposition on a $\mathrm{TiO}_{2}$ single-crystal surface. The effect of the electrode potential and holding time on the morphology of the electrodeposited $\mathrm{Pt}$ on the Nb-doped $\mathrm{TiO}_{2}(110)$ was examined, and we have found that the $\mathrm{Pt}$ nanoparticles with different aspect ratios (height/apparent diameter) can be prepared by choosing appropriate deposition conditions.

Figure 1 shows cyclic voltammograms $(\mathrm{CVs})$ of a $\mathrm{Nb}$ doped (0.05 wt $\%) \mathrm{TiO}_{2}(110)$ electrode in $50 \mathrm{mM} \mathrm{H} \mathrm{H}_{2} \mathrm{SO}_{4}$ and in a solution of $1 \mathrm{mM} \mathrm{K} \mathrm{PtCl}_{4}+50 \mathrm{mM} \mathrm{H} \mathrm{SO}_{4}$. In-Ga eutectic alloy was attached to the backside of the $\mathrm{TiO}_{2}(110)$ surface for ohmic contact and both electrolyte solutions were deoxygenated before the measurements. In the $50 \mathrm{mM} \mathrm{H}_{2} \mathrm{SO}_{4}$ solution, when the electrode potential was scanned in the negative direction, cathodic current started to flow at around

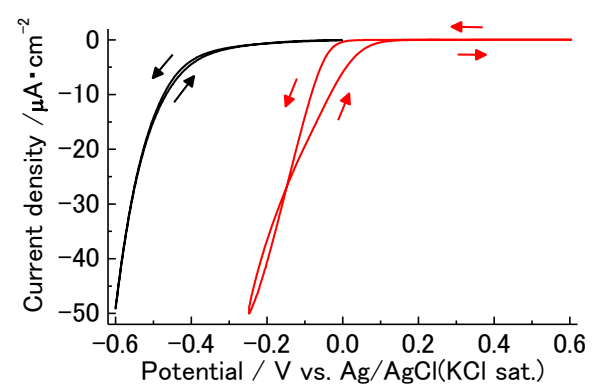

Figure 1. $\mathrm{CVs}$ of a $\mathrm{Nb}$-doped $\mathrm{TiO}_{2}(110)$ electrode in $50 \mathrm{mM} \mathrm{H}_{2} \mathrm{SO}_{4}$ (black line) and in $1 \mathrm{mM} \mathrm{K}_{2} \mathrm{PtCl}_{4}+50 \mathrm{mM} \mathrm{H}_{2} \mathrm{SO}_{4}$ solution (red line). Scan rate $10 \mathrm{mV} / \mathrm{s}$.

$-0.3 \mathrm{~V}$ due to the hydrogen evolution reaction (HER; $2 \mathrm{H}^{+}+$ $2 \mathrm{e}^{-} \rightarrow \mathrm{H}_{2}$ ). However, in $1 \mathrm{mM} \mathrm{K} \mathrm{PtCl}_{4}+50 \mathrm{mM} \mathrm{H}_{2} \mathrm{SO}_{4}$ solution, the cathodic current began to flow at around $0 \mathrm{~V}$ according to the following reaction:

$$
\mathrm{PtCl}_{4}{ }^{2-}+2 \mathrm{e}^{-} \rightarrow \mathrm{Pt}+4 \mathrm{Cl}^{-}
$$

Considering that the reversible potential for the reaction (1) in $1 \mathrm{mM} \mathrm{PtCl}_{4}{ }^{2-}$ was calculated to be $0.49 \mathrm{~V}$ vs. $\mathrm{Ag} / \mathrm{AgCl}(\mathrm{KCl}$ sat.), a large overpotential was required to initiate $\mathrm{Pt}$ deposition, probably due to the semiconductive properties of the $\mathrm{Nb}$-doped $\mathrm{TiO}_{2}(110)$ electrode.

Figures 2(a) and (b) show tapping-mode AFM images of the $\mathrm{Nb}$-doped $\mathrm{TiO}_{2}(110)$ surface after electrodeposition at $-0.15 \mathrm{~V}$ for 1 and $10 \mathrm{~s}$, respectively. The $\mathrm{TiO}_{2}(110)$ electrode was first immersed in the electrolyte solution at $+0.58 \mathrm{~V}$ and stepped to $-0.15 \mathrm{~V}$. After holding the potential for $1 \mathrm{~s}$ or $10 \mathrm{~s}$, it was then stepped back to $+0.58 \mathrm{~V}$ and the sample was removed from the solution. The electric charges passing across the electrode were $98 \mu \mathrm{C} / \mathrm{cm}^{2}$ and $348 \mu \mathrm{C} / \mathrm{cm}^{2}$ for deposition time $1 \mathrm{~s}$ and $10 \mathrm{~s}$, respectively. The $\mathrm{Pt}$ particles were homogeneously distributed on the surface in both cases. Histograms of the height and apparent diameter for the $\mathrm{Pt}$ nanoparticles in Figs. 2(a) and (b), which were determined by cross-sectional analysis in the images, are shown in Figs. 2(c) and (d), respectively. The apparent particle diameter is sometimes corrected by assuming an appropriate shape (hemisphere or sphere) both for deposited particles and the AFM tip; however, this was not performed, because in this study we observed Pt particles which have similar height but different diameter (different aspect ratios). Particles with a maximum size of ca. $24 \mathrm{~nm}$ in height and ca. $170 \mathrm{~nm}$ in apparent diameter were formed with a deposition time of $1 \mathrm{~s}$, where the average particle height and apparent diameter were $13 \pm 7 \mathrm{~nm}$ and $111 \pm 43 \mathrm{~nm}$, respectively. A longer deposition time $(10 \mathrm{~s})$ resulted in a more significant increase in height and height distribution than that in the apparent diameter and 
corresponding distribution (average height: $35 \pm 18 \mathrm{~nm}$, average apparent diameter: $102 \pm 37 \mathrm{~nm}$ ). Note that there was no significant change in particle density with deposition for 1 $\mathrm{s}\left((3.9 \pm 0.5) \times 10^{8} / \mathrm{cm}^{2}\right)$ and $10 \mathrm{~s}\left((3.5 \pm 0.5) \times 10^{8} / \mathrm{cm}^{2}\right)$, which indicates that nucleation rate was much slower than the growth rate.

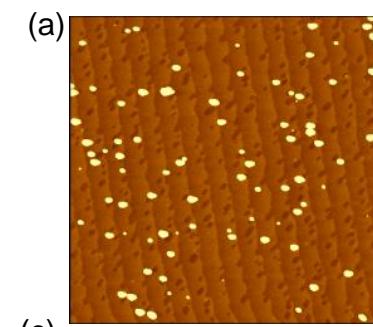

(c)
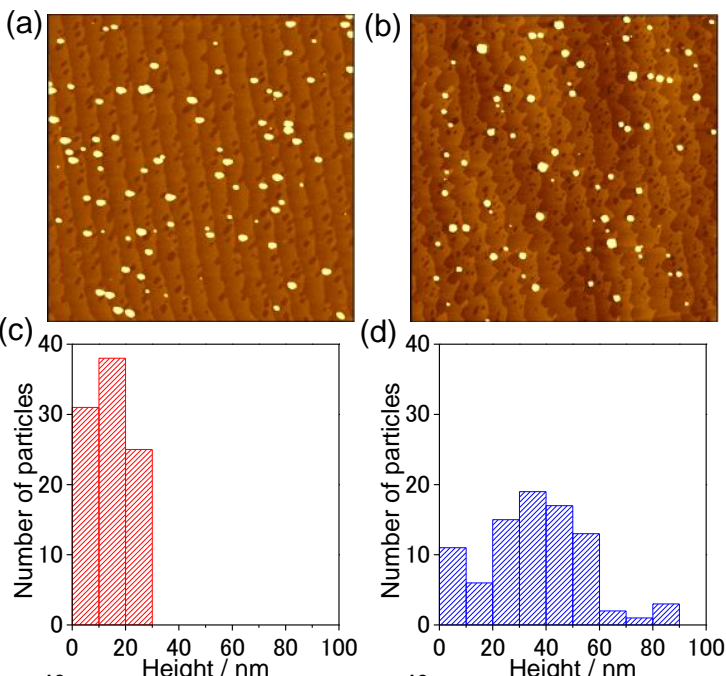

(d) 40
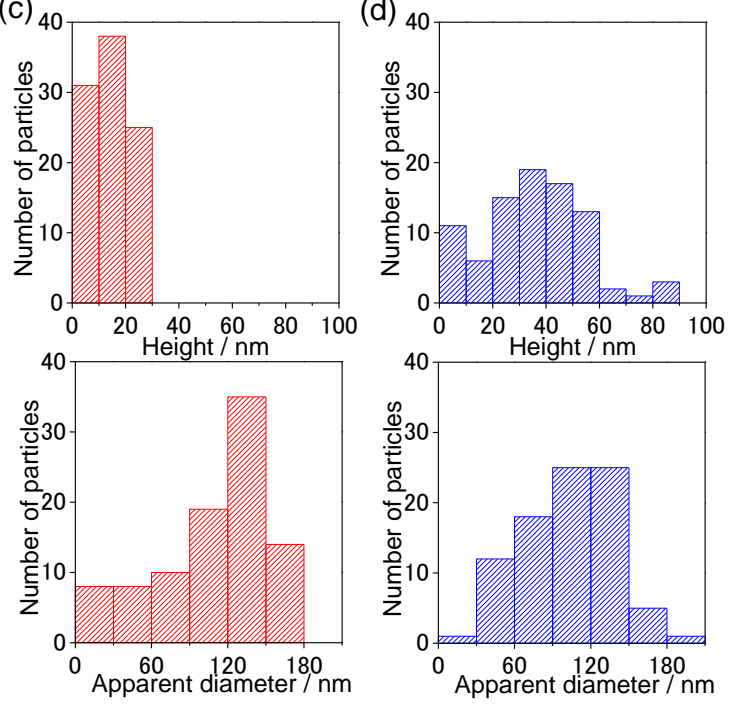

Figure 2. AFM images $\left(5 \times 5 \mu \mathrm{m}^{2}\right)$ of the $\mathrm{Nb}$-doped $\mathrm{TiO}_{2}(110)$ surface after electrodeposition at $-0.15 \mathrm{~V}$ for (a) $1 \mathrm{~s}$ and (b) $10 \mathrm{~s}$. (c) and (d) are histgrams of apparent diameter and height of the Pt nanoparticles observed in (a) and (b), respectively

Figure 3 shows the particle height as a function of the apparent diameter for the Pt particles at deposition times of 1 and $10 \mathrm{~s}$. The plots clearly indicate that vertical growth of the Pt particles is preferential over lateral growth when the deposition time is increased. This is probably due to more efficient electrodeposition on the predeposited $\mathrm{Pt}$ particles than on the $\mathrm{TiO}_{2}(110)$ surface due to the stronger interaction of the $\mathrm{PtCl}_{4}{ }^{2-}$ complex with the surfaces of $\mathrm{Pt}$ particles than with the $\mathrm{TiO}_{2}$ substrate, even if the $\mathrm{TiO}_{2}(110)$ surface is activated as discussed later. Vertical (three-dimensional) growth of $\mathrm{Pt}$ nanoparticles was also reported for the electrochemical deposition of $\mathrm{Pt}$ on a semiconductor n-type $\mathrm{Si}(111)$ electrode. ${ }^{10}$

Figures 4(a) and (b) show AFM images of the Nb-doped $\mathrm{TiO}_{2}(110)$ surface after electrodeposition at a smaller overpotential $(-0.05 \mathrm{~V})$ for 1 and $10 \mathrm{~s}$, respectively. The electric charges flowing across the electrode were $16 \mu \mathrm{C} / \mathrm{cm}^{2}$ and $269 \mu \mathrm{C} / \mathrm{cm}^{2}$ for deposition time $1 \mathrm{~s}$ and $10 \mathrm{~s}$, respectively. In Fig. 4(a), much smaller nanoparticles with narrower size distribution were obtained compared with those in Fig. 2(a) as indicated by the histograms in Fig. 4(c). The average particle height and apparent diameter were $1.5 \pm 0.6 \mathrm{~nm}$ and $20 \pm 4 \mathrm{~nm}$,

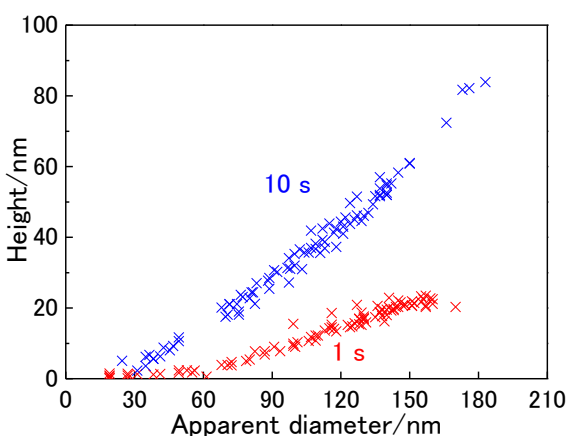

Figure 3. Plots of the particle height as a function of the apparent diameter for the Pt particles deposited at $-0.15 \mathrm{~V}$ for $1 \mathrm{~s}$ (red) and $10 \mathrm{~s}$ (blue). (a)

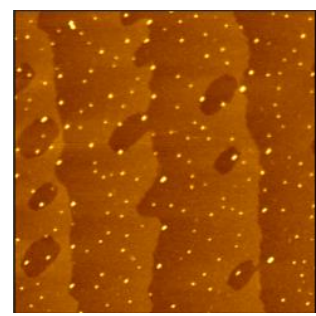

(c)
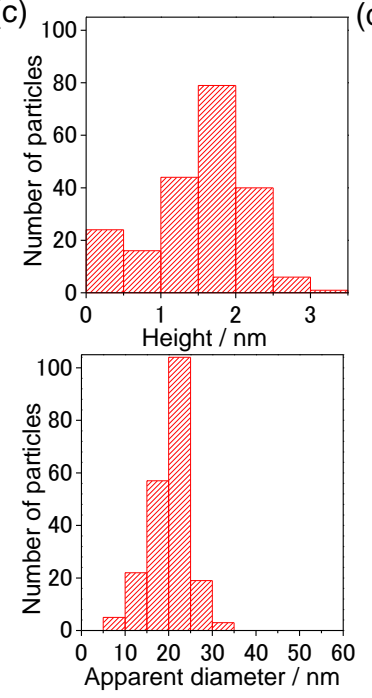

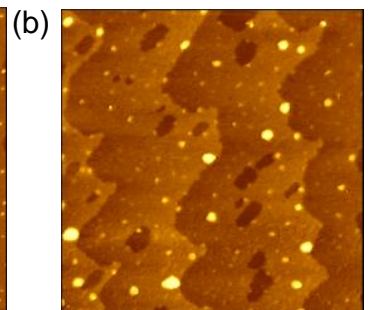

(d)
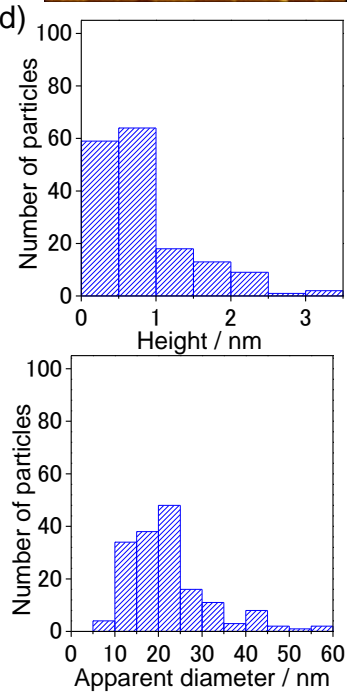

Figure 4. AFM images $\left(1 \times 1 \mu \mathrm{m}^{2}\right)$ of the $\mathrm{Nb}$-doped $\mathrm{TiO}_{2}(110)$ surface after electrodeposition at $-0.05 \mathrm{~V}$ for (a) $1 \mathrm{~s}$ and (b) $10 \mathrm{~s}$. (c) and (d) are histgrams of apparent diameter and height of the $\mathrm{Pt}$ nanoparticles observed in (a) and (b), respectively.

respectively. The particle density was $(9.9 \pm 0.8) \times 10^{9} / \mathrm{cm}^{2}$, which was much larger than that obtained at $-0.15 \mathrm{~V}$ in Fig. 2(a). Pt nanoparticles were formed on $\mathrm{TiO}_{2}$ terrace surfaces and no selective deposition at the step edges was observed, which is similar to the results for evaporated Pt deposition on a $\mathrm{TiO}_{2}(110)$ surface in an ultra-high vacuum (UHV) environment. ${ }^{11,12}$

When the deposition time is increased to $10 \mathrm{~s}$, the particle shape is significantly changed, as shown in the AFM image (Fig. 4(b)) and the corresponding histograms (Fig. 4(d)). The average particle height and apparent diameter were $0.8 \pm 0.6 \mathrm{~nm}$ and $22 \pm 9 \mathrm{~nm}$, respectively, and the particle density was $(8.9 \pm 0.8) \times 10^{9} / \mathrm{cm}^{2}$. Note that the number of the 


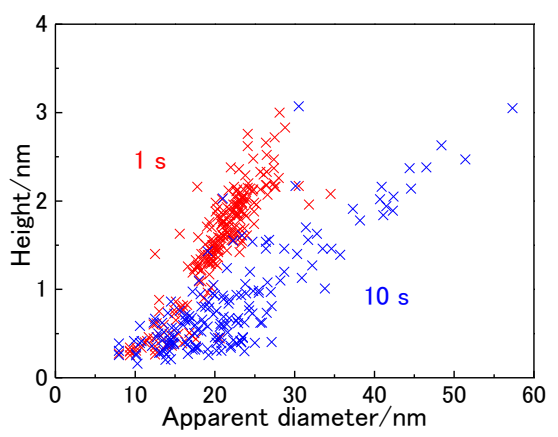

Figure 5. Plots of the particle height as a function of the apparent diameter for the Pt particles deposited at $-0.05 \mathrm{~V}$ for $1 \mathrm{~s}$ (red) and $10 \mathrm{~s}$ (blue).

particles with heights larger than $1.0 \mathrm{~nm}$ significantly decreased after electrodeposition for $10 \mathrm{~s}$, while the number of the particles with apparent diameters larger than $30 \mathrm{~nm}$ increased, as shown in Figs. 4(c) and (d). The particle height as a function of apparent diameter presented in Figure 5 indicates that the number of flat-shaped particles increases and lateral growth is preferential over vertical growth. It is also noted in Fig.5 that for a deposition time of $1 \mathrm{~s}$, most of the deposited Pt particles (99\%) were in the range of $<3 \mathrm{~nm}$ in height with apparent diameters of $<30 \mathrm{~nm}$, while for a deposition time of $10 \mathrm{~s}, 74 \%$ of the particles were $<1 \mathrm{~nm}$ in height with apparent diameters of $<30 \mathrm{~nm}$. Considering the results obtained at $-0.05 \mathrm{~V}$, the deposited $\mathrm{Pt}$ atoms were mobile and redispersed onto the $\mathrm{TiO}_{2}$ surface during the deposition process, and the $\mathrm{Pt}$ particles changed their shape form three-dimensional to flat two-dimensional one.

The origin of the change in particle shape during the electrodeposition process could be due to the delayed enhancement of the interaction between $\mathrm{Pt}$ and $\mathrm{TiO}_{2}$ at -0.05 $\mathrm{V}$. The interaction between $\mathrm{Pt}$ atoms and $\mathrm{TiO}_{2}(110)$ may not be so large at a deposition time of $1 \mathrm{~s}$, so that the deposited $\mathrm{Pt}$ atoms could migrate on the surface to find other Pt atoms to form nuclei or small particles. Because of the small size of nuclei or small particles, they were not yet stable, and the $\mathrm{Pt}$ atoms forming them could move to make further contact with the $\mathrm{TiO}_{2}$ surface when the deposition time is increased and the interaction between $\mathrm{Pt}$ and $\mathrm{TiO}_{2}$ becomes enhanced, resulting in the particle shape change from three-dimensional to twodimensional morphology. Adsorbed hydrogen on the $\mathrm{Pt}$ surface would facilitate migration of the $\mathrm{Pt}$ atoms by weakening the Pt-Pt bonds. ${ }^{13,14} \mathrm{We}$ speculate that hydrogen (or proton) spillover from the $\mathrm{Pt}$ particles to form $\mathrm{OH}$ groups on the adjacent $\mathrm{TiO}_{2}$ sites could be a possible reason for the delayed enhancement of $\mathrm{Pt}_{-} \mathrm{TiO}_{2}$ interaction. For example, hydrogen spillover from Pt nanoparticles onto a fluorinedoped tin oxide (FTO) surface under an electrochemical environment has been recently reported. ${ }^{15} \mathrm{Pt}$ might produce more $\mathrm{OH}$ groups on the $\mathrm{TiO}_{2}(110)$ than the bare $\mathrm{TiO}_{2}(110)$ without Pt due to the catalytic effect of Pt under the applied potential, and local density of $\mathrm{OH}$ groups around the deposited $\mathrm{Pt}$ particles would increase. $\mathrm{OH}$ groups on oxide surfaces have a stronger interaction with metal species and can act as metal nucleation sites, ${ }^{16-18}$ which would promote the change in particle shape from three-dimensional to twodimensional one. A similar situation should have been observed for Pt deposition at $-0.15 \mathrm{~V}$; however, the growth of Pt nanoparticles was much faster at $-0.15 \mathrm{~V}$ to form large stable Pt particles before the formation of a sufficient number of $\mathrm{OH}$ groups on the $\mathrm{TiO}_{2}(110)$ surface. In situ AFM measurements of the $\mathrm{Pt}$ deposition process are presently in progress to reveal the detailed growth mechanism at $-0.05 \mathrm{~V}$.

In conclusion, Pt was successfully electrodeposited on a $\mathrm{Nb}$-doped $\mathrm{TiO}_{2}(110)$ surface and the structure of the deposited Pt nanoparticles was examined using AFM. The height and apparent diameter distributions of the $\mathrm{Pt}$ nanoparticles changed significantly with the deposition potential and time. Vertical growth of $\mathrm{Pt}$ nanoparticles was preferential over lateral growth at $-0.15 \mathrm{~V}$, whereas the shape of the deposited Pt particles changed from three- to two-dimensional one at $0.05 \mathrm{~V}$ when the deposition time was increased. Pt nanoparticles with different aspect ratios (height/apparent diameter) can thus be prepared by the selection of appropriate deposition conditions, as shown in Figs. 3 and 5. A novel method for the preparation of metal nanoparticles on a $\mathrm{TiO}_{2}$ single-crystal surface in a controlled manner has been proposed.

This work was financially supported by a Grant-in-Aid for Scientific Research on Innovative Areas "Nano Informatics" (No. 25106010) from JSPS and NEDO (Demonstrative Research on Solid Oxide Fuel Cells/Fundamental Technologies Development/Analysis of Structure, Reactions, and Material Transfer of MEA Materials).

\section{References}

1 R.E. Rettew, N.K. Allam, F.M. Alamgir, F. M., ACS Appl. Mater. Interfaces, 2011, 3, 147.

2 C.-S. Chen, F.-M. Pan, Appl. Catal., B: Environ., 2009, 91, 663.

3 E. Formo, E. Lee, D. Campbell, Y. Xia, Nano Lett., 2008, 8, 668.

4 M.B. Vukmirovic, P. Liu, J.T. Muckerman, R.R. Adzic, J. Phys. Chem. C, 2007, 111, 15306.

5 A.M. Ruppert, B.M. Weckhuysen, in Handbook of Heterogeneous Catalysis, eds. G. Ertl, H. Knozinger, F. Schuth, J. Weitkamp, 2008; p 1178.

6 C.L. Pang, R. Lindsay, G. Thornton, Chem. Rev., 2013, 113, 3887

$7 \quad$ U. Diebold, Surf. Sci. Rep., 2003, 48, 53.

8 Y. Yamamoto, K. Nakajima, T. Ohsawa, Y. Matsumoto, H. Konuma, Jpn. J. Appl. Phys., 2005, 44, L511.

9 R. Nakamura, N. Ohashi, A.Imanishi, T. Osawa, Y. Matsumoto, H. Koinuma and Y. Nakato, J. Phys. Chem. B., 2005, 109, 1648.

10 S. Yae, M. Kitagaki, T. Hagihara, Y. Miyoshi, H. Matsuda, B. A. Parkinson, Y. Nakato, Electrochim. Acta, 2001, 47, 345.

11 S. Takakusagi, K. Fukui, R. Tero, K. Asakura, Y. Iwasawa, Langmuir, 2010, 26, 16392.

12 S. Gan, Y. Liang, D.R. Baer, A.W. Grant, Surf. Sci. 2001, 475, 159.

13 I.M. Tidswell, N.M. Markovic, P.N. Ross, Phys. Rev. Lett., 1993, 71,1601 .

14 K. Wu, M. S. Zei, Surf. Sci., 1998, 415, 212.

15 S. Mukherjee, B. Ramalingam, S. Gangopadhyay, J. Mater. Chem A, 2014, 2, 3954.

16 M. Heemeier, M. Frank, J. Libuda, K. Wolter, H. Kuhlenbeck, M. Baumer, H.J. Freund, Catal. Lett. 2000, 68, 19.

17 Z. Lodziana, J. K. Norskov, J. Chem. Phys. 2001, 115, 11261.

18 X. Tong, L. Benz, S. Chrétien, H. Metiu, M.T. Bowers, S.K. Buratto, J. Phys. Chem. C, 2010, 114, 3987. 